\title{
REFLEXÃO SOBRE A DEMANDA "CONTÍNUA" EM UMA UNIDADE DE SAÚDE DE UM MUNICÍPIO DA REGIÃO METROPOLITANA DE CURITIBA-PR
}

\author{
REFLECTION ABOUT THE USERS WITH "CONTINUOUS" DEMAND \\ IN A UNIT OF HEALTH OF A CITY OF THE REGION CURITIBA-PR METROPOLITAN \\ REFLEXIÓN SOBRE LA DEMANDA "CONTINUA" EN UNA \\ UNIDAD DE SALUD DE UN MUNICÍPIO ALEDAÑO DE CURITIBA-PR
}

\author{
Andréia Cristina Cruzara* \\ Maria Marta Nolasco Chaves**
}

\author{
* Enfermeira do Município de Piraquara-PR. \\ ** Professora Assistente do Departamento de Enfermagem da Universidade Federal do Paraná. Área de Saúde Coletiva
}

\begin{abstract}
RESUMO. O estudo é de natureza descritiva. Refere-se aos usuários com demanda "contínua" - usuários que procuram o serviço de saúde inúmeras vezes, podendo corresponder aos cinco dias da semana. Estes estão na unidade de saúde apresentando ou não, sinais, sintomas ou queixas. Objetivouse compreender as demandas dos usuários para a freqüência "contínua" na Unidade de Saúde Ferraria do município de Campo Largo, PR. O número de entrevistas foi definido pelo critério de saturação ${ }^{1}$. A análise do material obtido mostrou que a maioria dos usuários não possui companheiro e, apesar de conviverem com outras pessoas, demonstram carência afetiva que não é suprida no meio em que estão insertos. Assim, não possuindo afeto e união em casa, a ida à unidade de saúde apresenta-se como alternativa para suprir essa necessidade. Aliadas a esses sentimentos, outras questões de cunho econômico-social, tais como: baixa escolaridade, ausência de profissionalização, falta de emprego e ausência de meios que proporcionem o lazer na comunidade, para citar algumas delas, contribuem para que o sujeito adote a postura abordada neste estudo. Por outro lado, percebe-se que tal comportamento está relacionado diretamente à definição de políticas públicas, gerência dos serviços locais e modelos de atenção à saúde. Para a reversão do modelo atual de atendimento à demanda espontânea, individualizada e curativista, acredita-se que usuários, profissionais, gerentes, assim como Estado e sociedade, norteados pelas necessidades identificadas junto à população, devem estar juntos, refletindo a respeito das ações em saúde mais apropriadas.
\end{abstract}

PALAVRAS-CHAVE: saúde da família; sistema de saúde; planejamento em saúde.

ABSTRACT. This study it is characterized by its descriptive nature. The specific problem of the users with "continuous" demand is mentioned to it, or either, to the users who look to the innumerable service of health times, being able this amount of times to correspond to the five days of the week. Some presenting, in associated way, signals, symptoms or complaints, and others not. It was objectified, for way of this study, to understand the demands of the users for "the continuous" frequency in the Unit of Ferraria Health of the city of Campo Largo-Pr. The number of interviews was defined by the saturation criterion, according to Minayo (2004). The analysis of the gotten material sample that the majority of the users does not possess friends and, although to coexist other people, demonstrates to have an affective lack that is not supplied in the familiar scope and the social environment where they are inserted. It is cabível to consider that not possessing a narrow bow of affection and union in house, in contrast of that it happens with people who possess a steady and satisfactory conjugal and familiar relation, the gone one to the unit of health can be presented as an alternative to supply this necessity of affection and understanding. Allied to these feelings, other questions of economic-social matrix, such as: low escolaridade, absence of professionalization, lack of job and absence of ways that provide the leisure in the community, to cite some of them, contribute so that the citizen adopts the boarded position in this study. On the other hand, it is perceived that such related behavior also is fruit of the problematic ones to the definition of public politics, management of the local services and models of attention to the health. For the reversion of the current model of attendance to the spontaneous demand, individualizado and curativista, it is given credit that using, professional of health, health controlling, as well as State and society must, guided for the identified necessities together the population, to be together reflecting regarding the more appropriate actions in health.

KEYWORDS: family health strategy; health system; health planning.

RESUMEN. El estudio es de naturaleza descriptiva. Se refiere a los usuarios con demanda "continua" - usuarios que buscan varia veces el servicio de salud, llegando a corresponder a los cinco días de la semana. Estos están en la unidad de salud presentando o no señales, síntomas o quejas. Se ha objetivado, por medio de este estudio, comprender las demandas de los usuarios para la frecuencia "continua" en la Unidade de Salud Ferraria del municipio de Campo Largo,PR. El número de las encuestas fue definido por el criterio de saturación, de acuerdo con Minayo (2004). El análisis del material obtenido ha identificado que la mayoria de los usuarios no posee pareja y no obstante conviven con otras personas, demuestran carencia afectiva, la cual no es suprimida en el medio que conviven. Así pues, no poseyendo afecto y unión en casa, la ida a la unidad de Salud se presenta como una alternativa para suprimir esa necesidad. Aliadas a esos sentimientos, otras cuestiones de cuño económico-social, como: baja escolaridad, la falta de profesionalización, falta de empleo y ausencia de medios que proporcionen el ocio en la comunidad y otros, contribuyen para que el sujeto adopte la postura abordada en este estudio. Al revés, se percibe que el supuesto comportamiento está relacionado directamente a la definición de políticas públicas, gerencia de los servicios locales y modelos de atención a la salud. Para la reversión del actual modelo de atendimiento a la demanda natural, individualizada y curativa, se cree que los usuarios, profesionales, gerentes, bien como el Estado y la sociedad deben, direccionados por las necesidades identificadas en la populación, reflexionar sobre las acciones más adecuadas en salud.

PALABRAS-CLAVE: salud de la familia; sistema de salud; planeamiento en salud.

Recebido em: 30/01/2006

Aceito em: $\quad 29 / 03 / 2006$
Maria Marta Nolasco Chaves

Rua Padre Camargo, 280 - $7^{\circ}$ andar - Alto da Glória

80060-240 - Curitiba - PR

E-mail: mnolasco@terra.com.br 


\section{INTRODUÇÃO}

Para compreender por que determinado indivíduo ou família se comporta de forma específica, ou possui certas crenças sobre saúde e doença, os profissionais da saúde necessitam levar alguns fatores em consideração. Em geral, devem ser ponderados os fatores individuais, educacionais, culturais, sócioeconômicos e ambientais. Esta visão é importante porque determina o nível de intervenção que deve ocorrer, bem como a natureza desta intervenção ${ }^{2}$.

Segundo essa perspectiva de avaliação do paciente e de famílias, a conformação de equipes de saúde multiprofissionais apresenta-se, certamente, como fator determinante do sucesso da assistência à saúde a ser prestada.

É necessário que esse grupo de trabalhadores, que compõem a equipe de saúde, assumam um papel relevante no desencadeamento de ações que se caracterizem sob um ponto de vista além do biomédico. Essa questão é assinalada enfaticamente pelo Ministério da Saúde e configura-se como um dos pilares do Programa Saúde da Família ${ }^{3}$.

É importante ressaltar que, mesmo sendo de responsabilidade de toda a equipe, a articulação com indivíduos, família e comunidade cabe, de certa maneira, aos trabalhadores ligados à enfermagem e, mais especialmente, aos agentes comunitários que devem realizar o esforço inicial de articulação e integração e, ainda, o estabelecimento de vínculos com a comunidade ${ }^{3}$. Neste sentido, torna-se necessário que o enfermeiro se aproprie de instrumentos metodológicos que possibilite criar condições favoráveis para uma real aproximação com o mundoplural das pessoas e identificação dos motivos que as levam a procurar os serviços de saúde 4 .

Por meio de observação livre, sabe-se que os motivos que levam as pessoas a um serviço de saúde podem, ou não, estar associados a sinais, sintomas ou queixas, além da participação em atividades promovidas pelo serviço.

Há dois anos, durante um estágio voluntário na Unidade de Saúde Ferraria, do município de Campo
Largo, PR, constatou-se que existem usuários que buscam o serviço com alta freqüência; alguns apresentando, de maneira associada, sinais, sintomas ou queixas, outros não. Parte desses usuários justifica sua ida à unidade por não estar sentindo-se bem; como acompanhante de outro usuário; em busca de orientações à saúde e/ou porque está vinculado a uma ação programada da unidade. Outra parte não procura dar razões ao comparecimento; ao chegar ao serviço, deixa explícita a necessidade de acolhimento afetivo e de atenção dispensada pela equipe multiprofissional.

As duas categorias de usuários apresentavam um vínculo com a unidade e com os profissionais, deixando transparecer a necessidade de estar presente naquele serviço quase que diariamente. Neste sentido, a reflexão que norteou este estudo refere-se à investigação da motivação da demanda freqüente dos usuários na Unidade de Saúde, a fim de que este contribua com o serviço, na organização da atenção à saúde desses sujeitos.

A relevância da caracterização dos usuários com demanda "contínua" em uma unidade de saúde, vinculada ao Programa de Saúde da Família, na região metropolitana de Curitiba, PR, enquanto tema de investigação, justifica-se pela existência de indivíduos, que comparecem ao serviço com alta freqüência, por livre demanda e, demonstram a necessidade de estar junto à Unidade de Saúde e de manter contato com os profissionais, apresentando ou não, sinais, sintomas ou queixas, estando ou não vinculados aos programas de saúde promovidos pelo serviço.

Acredita-se que com a identificação da motivação dessa clientela para a ida à unidade de saúde, a equipe de profissionais e, mais especificamente, o enfermeiro, entre outras ações, poderá desenvolver atividades em que se trabalha com informações à saúde, e também nestas atendendo às "necessidades" desses usuários. Acredita-se que as ações programadas em saúde na Unidade de Saúde local poderiam atender a tais demandas. 


\section{METODOLOGIA}

Este estudo caracteriza-se por sua natureza qualitativa descritiva. O propósito da pesquisa descritiva é observar, descrever e explorar aspectos de uma situação, pois observa-se, registra-se, analisa e correlaciona fatos ou fenômenos sem manipulá-los, procurando descobrir, com a precisão possível, a freqüência com que um fenômeno ocorre, sua relação e conexão com outros, sua natureza e características ${ }^{5}$. Além disso, busca conhecer as diversas situações e relações que ocorrem na vida social, política, econômica e demais aspectos do comportamento humano, tanto do indivíduo tomado isoladamente, como de grupos e comunidades mais complexas.

O campo de estudo desta investigação constituiu-se da Unidade de Saúde Ferraria do município de Campo Largo, região metropolitana de Curitiba, Estado do Paraná, que apresenta uma equipe de Saúde da Família implantada. Os dados foram coletados por meio de observação livre no cotidiano do serviço de saúde delimitado para o estudo; entrevista com instrumento composto de perguntas abertas e fechadas e ainda com o desenho do genograma familiar, junto a oito sujeitos maiores de 18 anos, de ambos os sexos, residentes na área de abrangência da unidade de saúde em questão, que apresentaram as características pertinentes ao desenvolvimento do estudo, ou seja, usuários com demanda "contínua" à Unidade de Saúde Ferraria. O número de entrevistas foi definido pelo critério de saturação ${ }^{1}$, ou seja, quando os discursos apresentaram repetição das informações a coleta de dados foi suspensa, devido ao fato de não existirem novos elementos para a análise.

A coleta dos dados ocorreu concomitante à inserção das pesquisadoras no processo de trabalho da equipe multiprofissional da Unidade. Foi esclarecido ao usuário participante que seria assegurado o anonimato, sigilo e direito a desistir do estudo, sem prejuízo para ambas as partes, segundo as regulamentações da Resolução 196/96, que trata de pesquisa com seres humanos, do Ministério da Saúde ${ }^{7}$. Os formulários de Termo de Consentimento assinados pelos usuários foram mantidos em confidência estrita sob a guarda da pesquisadora.

A observação foi registrada em diário de campo para posteriormente ser analisada juntamente com os dados coletados em entrevista e nos prontuários. Esta teve como objetivo aprofundar o estudo sobre o contexto em que estão insertos os usuários; desta forma, tenta-se compreender por que buscam o serviço com tanta freqüência. Para isto, contou-se também, com observações realizadas junto aos profissionais da equipe multiprofissional.

A coleta de dados foi realizada no período da manhã no serviço de saúde em tela e procurou-se antes de efetuar a abordagem ao usuário, convidandoo para participar do estudo, atender a sua demanda nas suas mais variadas modalidades, ou seja, assistindo esse indivíduo com os instrumentos que o serviço oferece, ou mesmo o escutando em suas queixas, anseios, e preocupações, como profissional e ser humano. Adotando essa postura, foi fácil realizar a abordagem e estabelecer certa relação de confiança com esses indivíduos.

Os espaços ocupados para o preenchimento do questionário e construção do genograma variaram de acordo com a sua utilização, pelos profissionais que lá trabalham. Todavia foi assegurada a privacidade do usuário ao fornecer os dados para o estudo, em ambiente isolado das demais atividades que ocorriam concomitantemente no serviço.

Com vistas a tornar mais didáticas a organização e apresentação dos dados, inicialmente eles foram coletados por meio de observação livre, através de registros da Unidade e posteriormente foram analisadas as entrevistas. Após essa etapa, os dados pertencentes a cada usuário foram agrupados e compilados em um único arquivo. Seguiu-se então, a etapa de tabulação das informações, por meio da qual foi possível identificar as características convergentes e divergentes dos usuários, para sua posterior categorização. Com os dados agrupados partiu-se para a análise, à luz do referencial teórico. 
Os dados coletados foram analisados segundo do ponto de vista do processo saúde/doença. A autora nos diz que, por meio da interpretação dialética, devemos entender que saúde/doença e demais questões vinculadas a esse processo são um fenômeno social, não porque apenas expressam o nível de vida ou correspondem a certas profissões e práticas, mas porque são manifestações da vida material, das carências, dos limites sociais e do imaginário coletivo. São resultado de condições anteriores e exteriores ao grupo, sem deixar de ser específicas. São frutos de condições dadas, mas também produto de sua ação transformadora sobre o meio social. Isso implica que, a saúde e a doença envolvem uma complexa interação entre os aspectos físicos, psicológicos, sociais e ambientais da condição humana e de atribuição de significados ${ }^{1}$.

Do ponto de vista, do processo saúde-doença, Minayo ${ }^{1}$ nos diz que, por meio da interpretação dialética, devemos entender que saúde-doença e demais questões vinculadas a esse processo são fenômeno social, não porque apenas expressam o nível de vida ou correspondem a certas profissões e práticas, mas porque são manifestações da vida material, das carências, dos limites sociais e do imaginário coletivo. São resultado de condições anteriores e exteriores ao grupo, sem deixar de ser específicas. São frutos de condições dadas, mas, também, produto de sua ação transformadora sobre o meio social ${ }^{1}$. Esses aspectos devem ser considerados no desenvolvimento do estudo em tela.

Para a construção deste estudo, foi indispensável a revisão de literatura sobre os temas e os sub-temas inerentes ao processo desenvolvido. Entre estes se destacam: Medicina Familiar e Programa Saúde da Família que foram norteadores na análise dos dados coletados.

\section{ANÁLISE E DISCUSSÃO}

Por meio da tabulação dos dados e sua posterior categorização, percebeu-se que a maioria dos usuários não possui companheiros e, apesar de conviverem com outras pessoas, demonstram ter carência afetiva, que não é suprida no âmbito familiar e no meio social em que estão insertos. É cabível considerar que, não possuindo um laço estreito de afeto e união em casa, ao contrário do que acontece com pessoas que possuem uma relação conjugal e familiar estável e satisfatória, a ida à unidade de saúde pode apresentar-se como alternativa para suprir essa necessidade de afeto e compreensão.

Aliadas a esses sentimentos, outras questões de cunho econômico-social, tais como: baixa escolaridade, ausência de profissionalização, falta de emprego e ausência de meios que proporcionem o lazer na comunidade, para citar algumas delas, contribuem para que o sujeito adote o comportamento verificado nesse estudo, ou seja, usuários que procuram o serviço de saúde inúmeras vezes, podendo essa quantidade de vezes corresponder aos cinco dias da semana em que a unidade está aberta para atendimento. Isso significa dizer que os usuários com demanda "contínua" são aqueles que estão na unidade de saúde quase todos os dias da semana, apresentando ou não, de maneira associada, sinais, sintomas ou queixas. Esse comportamento repetese semana após semana e esses indivíduos já fazem parte do cotidiano do serviço.

Para fundamentar o exposto acima verificou-se que o grupo possuía uma renda familiar mensal em torno de $\mathrm{R} \$ 600,00$ e que o número de dependentes dessa renda é, em média, de três pessoas. Em um caso, verificou-se que são dois os provedores, mas essa situação não foi exceção no grupo. Quanto ao grau de escolaridade, seis usuários possuem o ensino fundamental incompleto, um o ensino médio incompleto e um o ensino médio completo. Quanto à profissão ou ocupação que desempenhavam, foram citadas as seguintes: balconista, dona de casa, doméstica, auxiliar de cozinha, construtor, porteiro e metalúrgico, além de estudante. Cabe mencionar que nenhum usuário referiu formação técnica, seja em qualquer ramo, logo as funções que mencionaram não estão relacionadas a nenhuma profissão específica e sim a uma ocupação. Na identificação 
da condição atual de trabalho, verificou-se que seis usuários estão desempregados, um está aposentado e um é estudante.

Considerando os estudos de Chaves ${ }^{8}$, é possível tornar ainda mais clara essa questão pois ela nos diz que o processo saúde-doença é a resultante das condições de vida de uma determinada população e que o bem-estar dos indivíduos é a resultante das suas condições de vida, em um determinado local, em determinado período de tempo, influenciada pelas questões sócioeconômicas. Logo, se os sujeitos não possuem essas condições, se sentem "doentes" e procuram os lugares que crêem sanar suas necessidades, no caso, os serviços de saúde. A partir desse ponto de vista, percebe-se uma postura coerente: se as suas percepções sobre si são de doentes, ou acreditam não estarem desfrutando de um bem estar pleno, procuram o local onde teoricamente obteriam as condições para gozar de uma vida mais saudável e conseqüentemente mais feliz, a unidade de saúde.

Observam-se que a situação de vida dessas pessoas, com renda precária e sem perspectivas de mudanças da realidade em que vivem, deve-se ao pouco preparo que têm diante do contexto atual; do mundo globalizado, informatizado e em constante transformação. Assim, baixa escolaridade, ausência de formação específica e falta de políticas de geração de emprego e renda local concorrem para a ocorrência da situação de desemprego vivido por esses sujeitos. Contudo, não possuindo trabalho em que se dedicariam a uma atividade que os viabilizaria economicamente, que os tornem sujeitos e cidadãos de fato, tendem a passar os dias ociosos e, como conseqüência, relacionam suas vidas aos adoecimentos e, de modo geral, buscam nos serviços de saúde a ajuda para suas necessidades, independente da natureza delas. A fala a seguir nos permite compreender melhor essa questão:

Hoje procurei a Unidade porque não estou me sentindo bem, são tantas coisas que deixam a gente assim, se eu parar para dizer tudo o que eu tenho minha filha, ficamos aqui o dia inteiro (...) Nem mais trabalhar eu posso. A gente tem pouco estudo, não tem trabalho e ainda doente. Não é fácil. Fora todos os problemas que a gente tem em casa (E1).

Nesse sentido, acredita-se que o Programa Saúde da Família, que preconiza um modelo integral de atenção à saúde, poderia ajudar esses sujeitos. Por ser uma estratégia que tem metas e práticas para contribuir com a melhoria das condições de vida e do nível de saúde da população, deveria voltar seus esforços e enfocar o cidadão em suas relações familiares e comunitárias, assim como discutir os determinantes e os condicionantes desta realidade.

Observa-se que, apesar das tentativas dos profissionais da saúde, existe grande dificuldade em reverter o modelo atual de assistência, modelo curativista individualizado, para uma proposta de trabalho em que as ações e atividades estão voltadas para o sujeito e o contexto em que ele está inserto. Desta forma, a assistência fica centrada no atendimento à demanda espontânea e torna-se difícil construir uma aproximação individual e coletiva entre profissionais e usuários, que permita aos primeiros identificar as reais necessidades daqueles que os procuram.

É evidente que se não há oferta de atividades ou grupos de convívio social que promovam reuniões, cursos e espaços de participação, seja na unidade ou em outros espaços coletivos onde possam discutir a realidade da comunidade. Esses usuários se dirigem aos lugares em que sabem que encontrarão outras pessoas, com as quais podem estar, como é o caso da unidade de saúde. Verifica-se que esses sujeitos não necessitam de cuidados clínicos que envolvam medicamentos e procedimentos complexos ofertados pela medicina atual. Essas pessoas precisam que outras pessoas focalizem seu olhar e procurem, compreender, dar atenção e conquistar um espaço para que falem e demonstrem seus anseios e inquietações, assim como possibilitem trocas. A fala do usuário demonstra esta análise:

Eu gosto de vir até aqui, porque posso conversar com as meninas que trabalham aqui no postinho, aqui no 
meu bairro não tenho ninguém para conversar, você sabe que eu vim da Bahia. E elas são gente boa (E2).

Tendo em vista as primeiras observações e reflexões sobre o assunto, cabe mencionar que muitos profissionais procuram sanar a necessidade do usuário, ofertando-Ihe uma medicação. Esta conduta agrada a muitos usuários e possibilita ao profissional "livrar-se" rapidamente dos sujeitos, não se envolver com seus problemas de ordem mais complexa e dar a impressão de que os problemas serão resolvidos com o uso dos remédios. Porém, desta forma, acredita-se que o profissional coloca o indivíduo em situação passiva, e o transfere da condição de sujeito para a condição de objeto. Este, como conseqüência, assume descomprometida postura, referente às situações ao seu redor. Este modelo de atenção não leva a uma melhoria na qualidade de vida. Pelo contrário, mascara outras questões, sobre as quais os usuários não estão acostumados a refletir e que são importantes para o enfrentamento dos momentos que vivem. Essa atitude reforça o comportamento dos usuários que justificam a ida à unidade pelo fato de estarem doentes e/ou alguém da família estar. Neste sentido, estariam lá presentes para que fossem atendidos em uma demanda de sinais, sintomas ou queixas.

É bem verdade que grande parte desse cenário ainda se deve ao fato de o saber clínico ter maior importância que o saber epidemiológico. Desta forma, torna-se prática corrente fornecer consultas e medicamentos à população. E, uma vez acostumados a esse modelo, os indivíduos acreditam que as vantagens de ação em saúde estão centradas nas consultas médicas. Levando-se em consideração essa discussão, não basta prevenir as doenças e medicalizar a população. Antes de qualquer coisa, é necessário assegurar qualidade de vida básica a esses sujeitos, o que implica não somente que a proporcione, mas que a sociedade tenha entranhas e coração. Somente dessa forma as pessoas gozariam de saúde e bem-estar ${ }^{9}$.

Nesse caso, sem dúvida, a condição socioeconômica das famílias dos usuários é preponderante para o entendimento do seu comportamento. São numerosas as famílias, aqui estudadas, possuem uma renda familiar declarada (de $\mathrm{R} \$ 300,00$ a $\mathrm{R} \$ 800,00$ ) que não lhes permite satisfazer plenamente as suas necessidades, como alimentação, vestimentas, transporte e lazer. Podese afirmar que a vida que levam está muito aquém de ser "saudável"; pode-se dizer que esses indivíduos estão muito distantes de serem assistidos pelo serviço de saúde local, de modo integral.

Pelo conceito de integralidade, as intervenções de um sistema de saúde no processo saúde-doença conformam uma totalidade que engloba os sujeitos do sistema e suas inter-relações com o ambiente natural e social, assim como compreende a unicidade institucional dos serviços de saúde para o conjunto de ações promocionais, preventivas, curativas e reabilitadoras ${ }^{10}$.

Sabe-se que para o enfrentamento dos problemas de saúde deve-se operar uma articulação de ações setoriais e intersetoriais, que estão situadas fora dos limites convencionais do setor saúde. Quanto a isso, por meio da prática que tornou possível a realização desse estudo, verificou-se que os usuários da unidade de saúde em exame estão descrentes das ações políticas oriundas do município e não mais acreditam nas declarações das autoridades locais, referentes ao melhoramento do bairro e às condições de vida da população, conforme se constatou em suas falas.

Você veja só, a nossa condição aqui, nós estamos esquecidos, ninguém liga para o nosso bairro, nem a rua que está cheia de buracos eles se preocupam, até tem o perigo de um acidente nessas curvas. Mas fazer o quê? A gente mesmo tem que se virar (E3).

A gente tem de chegar aqui de madrugada para conseguir atendimento (...) já teve até que perder um dia no trabalho para vir aqui (...) Esse postinho não dá mais, será que eles não vêm que precisa de um $24 \mathrm{~h}$ (...) Mas sei lá, ninguém não está nem aí com a gente (E4).

Outro fato que referenda esta afirmação é que os usuários do bairro Ferraria, e demais moradores 
das áreas circunvizinhas, apesar de serem referenciados para o centro médico de Campo Largo, em caso de emergência/urgência e/ou consulta com especialidades, procuram a cidade de Curitiba para sanar seus problemas. Esse fenômeno se deve ao fato de que o Centro Médico de Campo Largo, unidade referenciada pelos serviços locais, fica mais distante e o acesso torna-se mais difícil, do que aos serviços do município de Curitiba. Outro fato que contribui para tal é que os ônibus que vão para o centro do município de Campo Largo demoram intervalos que chegam a 60 minutos. Pelo contrário, os ônibus para Curitiba, chegam em menores intervalos de tempo, facilitando, o deslocamento. Além disso, os sujeitos mencionaram em suas falas que tem maior credibilidade na assistência prestada pelo município de Curitiba.

Bom, quando eu preciso de um atendimento urgente, eu nem vou para Campo Largo (E3).

Eu já estou acostumada a ir até o 24h do Campo Comprido, lá eu sei que se acontecer alguma coisa, eles já mandam para o (...) ou até mesmo socorrem a gente lá. Eu acho que em Campo Largo não tem todos os aparelhos que a gente precisa (E5).

Quanto às informações que dizem respeito à freqüência do usuário na Unidade de Saúde, houve discordâncias com relação à freqüência referida e observada, ou seja, em relação ao número de vezes, que esses usuários mencionaram ir à Unidade e o que a pesquisadora observou. As informações fornecidas durante o preenchimento do questionário divergem das obtidas mediante observações livres e consultas aos registros do serviço durante os meses de agosto e setembro de 2005, período do estudo. Aqueles que disseram ir a unidade três vezes ao mês, pelo menos foram observados duas vezes na semana na unidade, no período da manhã ou no período da tarde. Cabe fazer uma ressalva nesse momento, dizendo que é de certa forma compreensível a relutância em admitir, pessoalmente, que passam grande parte de seu tempo, na unidade, longe de casa e de alguma atividade produtiva, lucrativa e que entendem como dignificante. Afirma-se esta observação porque na pergunta: Com que freqüência você vai a unidade de saúde? Foi possível perceber certo grau de constrangimento, alguns responderam em meio a sorrisos. Em contrapartida, um dos usuários foi bem sincero e enfático ao responder a essa questão, ele disse;

Gosto de ir à Unidade para passear, como estou desempregado e, não tenho nada para fazer, sinto-me bem indo ao serviço e passando meu tempo junto de outras pessoas, especialmente junto aos funcionários com quem tenho amizade (E6).

Ao refletir sobre esta fala, é possível perceber o papel dos profissionais da saúde e, em especial do enfermeiro, pela oportunidade de que esses contatos com os indivíduos sadios ou mesmo doentes poderiam permitir atividades para promover a saúde, abordando aspectos da educação sanitária. A equipe de saúde também pode fazer deste encontro um compromisso para o desenvolvimento de uma estratégia capaz de instrumentalizar a população para participar nas instâncias existentes e garantidas pelas políticas nas quais estes discutiriam as questões relacionadas à saúde e à organização do sistema local.

É importante mencionar ainda que a topografia do local em que se encontra a Unidade é bastante irregular, inexiste a pavimentação, as ruas são de "chão batido", e não há acostamento ou calçadas. Especialmente em dias de chuva, é difícil chegar a esse local, pois a Unidade se encontra literalmente em uma "descida" e as ruas que as circundam tornamse "enlameadas" e bastante escorregadias. Todos os usuários vão a pé. Esse dado sugere que muitos dos usuários com demanda "contínua", nos dias de chuva, se restringem a ir ao serviço; àqueles que vão o fazem com sacrifício. Levando-se em consideração que no período de coleta de dados, houve a ocorrência de chuvas constantes com baixa temperatura; percebe-se o grau de importância em ir à unidade, que é dado por alguns sujeitos.

Com relação a procurar outros recursos que não os serviços de saúde, para aliviar ou resolver sinais, sintomas e queixas, tais como: benzedeiras, 
igreja, farmácias, amigos, vizinhos, entre outros, apenas um usuário mencionou procurar a benzedeira nos momentos que considera essa a única prática capaz de resolver seu problema de saúde ou o problema de algum de seus familiares:

Sabe, eu não sei, mas eu acredito nessas coisas, tem coisas que só benzedeira. Quando eu estou com rasgadura, não adianta vir no médico, não adianta nada, e eu vou lá, me benzo e melhor. Os meus filhos eu levo também (E7).

Todos os entrevistados negaram ir à farmácia sem a indicação médica. Todavia se sabe que há duas farmácias locais e que essa prática por parte da população é comum.

A princípio, foi imaginado que o genograma ajudaria em muito na obtenção de dados relevantes para o encontro e complementação de algumas informações já mencionadas no corpo do questionário. No entanto percebeu-se que muitos se mostraram pouco à vontade em falar a respeito de certos aspectos de sua vida familiar, fato esse que não favoreceu a obtenção de maiores informações quanto às características das famílias. Além do que, quando era mencionado que seriam interessantes outras informações além daquelas já fornecidas anteriormente, o usuário se mostrava impaciente e pouco confortável com a demora, apesar de logo após sua "liberação" da entrevista permanecerem na unidade por no mínimo mais uma ou duas horas.

Sobre este comportamento, reflete-se que os próprios usuários têm receio em falar das reais necessidades que têm em suas vidas e com seus familiares e o que os levam a procurar a U.S. Destacam-se outras reflexões sobre esta observação. Os usuários temem que ao dizer algo, possam ser "limitados" e não mais serem aceitos nesse ambiente, que elegeram como acolhedor e de encontro, por não possuírem uma condição de doente que os torne usuários "legítimos" do serviço. Moderam-se também pelo fato de saberem que a ida à Unidade de Saúde está além da busca por consumo de medicamentos e consultas médicas.
A partir daí, surge o desafio de definir o cuidado que o sujeito necessita, buscando os significados, muitas vezes, nos discursos, no contexto socioeconômico, psicológico e cultural vivenciado.

\section{CONSIDERAÇÕES FINAIS}

Com o intuito de realizar um estudo condizente com a realidade do serviço local de saúde, optou-se por desenvolver esta temática de atenção à saúde coletiva no Programa Saúde da Família, que teve como objeto de estudo a demanda "contínua". Apesar de ser característica marcante da Unidade de Saúde Ferraria, esse comportamento por parte de alguns usuários é visto em muitos outros serviços de saúde e se repete, muito provavelmente, pelas mesmas causas aqui encontradas; daí a importância do estudo. Por meio da compreensão dos motivos que levam o usuário a freqüentar, quase que diariamente, a unidade de saúde e por meio do entendimento de como se dá sua inserção no espaço da Unidade de Saúde e da comunidade, foi possível refletir sobre o modo como está organizado o modelo atual de atenção à saúde.

Há pelo menos uma década o Ministério da Saúde adotou uma política que tem como estratégia reverter o modelo de atenção curativista individualizado para uma proposta integral de atenção à saúde, na qual os sujeitos sejam assistidos, levando-se em consideração o contexto socioeconômico, psicológico e cultural em que estão insertos. Com esse objetivo foi criado e implantado o Programa Saúde da Família. Esse modelo preconiza que a estratégia para a garantia da assistência integral à saúde, nos serviços e na comunidade, deveria voltar seu olhar às necessidades da população e instrumentalizá-la para a transformação da sua realidade.

Na Unidade de Saúde em que foi realizado o estudo, sabe-se que não é caso isolado; o Programa Saúde da Família funciona precariamente, nele se destacam as questões relacionadas à falta de recursos materiais, espaço físico inadequado e falta de profissionais para a realização das atividades que 
são preconizadas pelo próprio programa. Dentre essas atividades, observam-se as dificuldades relacionadas ao deslocamento de pessoal para uma visita domiciliar. Falta de espaço físico para o desenvolvimento de um grupo de atendimento familiar e a equipe de saúde incompleta tem, como conseqüência, a não cobertura de muitas áreas que fazem parte do território adscrito para o serviço em apreciação.

No período do desenvolvimento do estudo, o que se observou é que há uma mobilização dos profissionais para a realização de visitas domiciliares, palestras educativas em espaços da comunidade e monitoramento dos agentes comunitários, assim como, a tentativa de resolução dos problemas que esses últimos trazem ao serviço. Todavia sabe-se que o Programa Saúde da Família preconiza muito mais do que isso. Se levado verdadeiramente a cabo, conforme o preconizado nas disposições do SUS, muito tem a contribuir com a saúde dos indivíduos. Contudo a realidade deste serviço não contribui para se efetivar de fato o programa; pelo contrário, o que se observou foi que todos os esforços da equipe de saúde local são para o atendimento da demanda espontânea que cresce dia após dia e, não se dá conta de solucionar os problemas de saúde.

O que dizer então da demanda "contínua"? Aquele usuário que apresenta sintomatologia visível consegue ser atendido em suas necessidades. Mais difícil ainda, é assistir o sujeito que comparece à unidade e não deixa explícitas suas reais necessidades, como é o caso dos usuários com demanda "contínua". Porém é evidente que a freqüência diária reflete a carência que os usuários, caracterizados neste estudo como demanda "contínua", procuram atender com suas idas à Unidade de Saúde.

A análise dos dados coletados mostrou que as carências advêm de ordem econômica, social, psicológica e até mesmo espiritual e que há o descaso na atenção e organização do serviço de saúde em face desses sujeitos. Outra questão que ficou evidente, foi que tanto os usuários quanto os profissionais estão "engessados" pela rotina diária e não ousam libertar-se por uma série de motivos, desde a acomodação até o temor ou falta de habilidades para gerar discussões em níveis superiores de gestão, que visem à transformação das condições de trabalho e melhoria da qualidade da assistência. Como resultado, os usuários com demanda "contínua" permanecem no serviço e os profissionais continuam a se eximir da responsabilidade de discutir as motivações que os levam a procurar o serviço, e se abstêm de atendê-los em suas reais necessidades, ou seja, o usuário não sai e o profissional não discute a permanência destes sujeitos; assim, não há possibilidade de desenvolver uma atenção à saúde que atenda as reais demandas deste grupo.

Como reverter esse quadro? A reflexão construída neste estudo sobre a demanda "contínua" no serviço de saúde remete, sem dúvida, para uma antiga problemática: a definição das políticas públicas, a gerência dos serviços locais, os modelos de atenção à saúde que deveriam ser norteados pelas necessidades identificadas junto à população.

Vale dizer que muito se produz, intelectual e praticamente, em termos de modelo de gestão ou até de organização dos serviços, mas pouco se tem pensado a respeito da dimensão da ação clínica e da ação epidemiológica e qual seria sua integração, desenvolvendo-se assim, a integralidade em saúde neste espaço de intervenção.

Ao trazer a dimensão da integralidade para o interior das ações em saúde, busca-se a interação dos profissionais, usuários, gestores e ainda do Estado com sociedade. Todos têm sua parcela de responsabilidade em face das questões de saúde. Somente por meio dessa interação é que surgirão reflexões críticas e propostas de ações que vão desde a política e seu caráter público, até as organizações projetadas e a legitimidade das suas normatizações para permitir ações integradas de saúde.

A temática deste estudo merece investigações mais aprofundadas, para que se possa compreender melhor esse fenômeno que é a demanda "contínua" na Unidade de Saúde, no sentido de contribuir para 
a prática sanitária que perceba e atenda a esses indivíduos nas suas demandas.

\section{REFERÊNCIAS}

1 Minayo MCS. O desafio do conhecimento: pesquisa qualitativa em saúde. São Paulo: Hucitec; 1996. p.269.

2 Helman CG. Antropologia médica e atenção primária à saúde. In: Duncan BB, et al. Medicina ambulatorial: condutas clínicas em atenção primária. Porto Alegre: Artes Médicas; 1996. p.43-6.

3 Mishima SM, Campos AC. O trabalho no programa de saúde da família - perfil das equipes. Rev Min Enferm 2003. Belo Horizonte 2003; 7(2):124-33.

4 Alonso IK. O cuidado de enfermagem na saúde da família - sob o olhar da antropologia da saúde. Rev Téc-cient Enferm 2003; 1(1):60-5.
5 Polit DF, Hungler BP. Fundamentos de pesquisa em enfermagem. Porto Alegre: Artes Médicas; 1995. p.330.

6 Cervo AL, Bervian PA. Metodologia científica. São Paulo: Prentice Hall; 2002. p.254

7 Ministério da Saúde (BR). Conselho nacional de saúde. Resolução n. 196 de 10 de outubro de 1996. Dispõe sobre pesquisa envolvendo seres humanos. Diário oficial da república federativa do Brasil.

8 Chaves MMN. Enfermagem em saúde pública. Secretaria de Estado da Saúde (SESA); Instituto de Saúde do Paraná (ISEP); Centro Formador de Recursos Humanos Caetano Munhoz da Rocha; 2002. p.114.

9 Luz MT. Novos saberes e práticas em saúde coletiva: estudos sobre racionalidades médicas e atividades corporais. São Paulo: Hucitec; 2003. p.174.

10 Mendes EV. Distrito sanitário: o processo social de mudança das práticas sanitárias do sistema único de saúde. São Paulo: Hucitec; 1995. p.311. 